\title{
Aluminum Migration and Intrinsic Defect Interaction in Single-Crystal Zinc Oxide
}

\author{
K. M. Johansen, L. Vines, T. S. Bjørheim, R. Schifano, and B. G. Svensson \\ Centre for Materials Science and Nanotechnology, University of Oslo, 0318 Oslo, Norway
}

(Received 10 October 2014; published 12 February 2015)

\begin{abstract}
Vacancy-mediated migration of $\mathrm{Al}$ in single-crystal zinc oxide $(\mathrm{ZnO})$ is investigated using secondary-ion mass spectrometry (SIMS) combined with hybrid density-functional theory (DFT) calculations. A thin film of Al-doped $\mathrm{ZnO}$ is deposited by sputtering onto the single-crystal bulk material and heat treated at temperatures in the range of $900{ }^{\circ} \mathrm{C}-1300^{\circ} \mathrm{C}$. The migration of $\mathrm{Al}$ is found to be $\mathrm{Zn}$-vacancy mediated. In order to elucidate the physical processes involved, an alternative model based on reactive diffusion is developed. The model includes the time evolution of the concentration of $\mathrm{Al}$ atoms on the $\mathrm{Zn}$ site $\left(\mathrm{Al}_{\mathrm{Zn}}\right), \mathrm{Zn}$ vacancies $\left(v_{\mathrm{Zn}}\right)$, and a complex between the two, where the influence of the charge state of $v_{\mathrm{Zn}}$ on its formation energy is incorporated through the free carrier concentration. The modeling results exhibit close agreement with the experimental data and the $\mathrm{Al}_{\mathrm{Zn}} v_{\mathrm{Zn}}$ complex is found to diffuse with an activation energy of $2.6 \mathrm{eV}$ and a preexponential factor of $4 \times 10^{-2} \mathrm{~cm}^{2} \mathrm{~s}^{-1}$. The model is supported by the results from hybrid DFT calculations combined with thermodynamical modeling, which also suggest that a complex between $\mathrm{Al}_{\mathrm{Zn}}$ and $v_{\mathrm{Zn}}$ is promoted in $n$-doped material. The charge state of this complex is effectively -1 , and it thus acts as a compensating acceptor, limiting full utilization of the shallow $\mathrm{Al}_{\mathrm{Zn}}$ donor. Furthermore, the DFT calculations also predict a high formation energy for both substitutional $\mathrm{Al}$ on the $\mathrm{O}$ site $\left(\mathrm{Al}_{\mathrm{O}}\right)$ and interstitial $\mathrm{Al}\left(\mathrm{Al}_{i}\right)$, and are therefore of minor importance for $\mathrm{Al}$ migration in $\mathrm{ZnO}$. The close coupling between the hybrid DFT calculations and the developed diffusion model enable benchmarking of the accuracy of several parameters extracted from the DFT calculations. Furthermore, since the diffusion model hinges strongly on defect concentrations, it couples directly to results from measurements by other experimental techniques than those used in this paper and provides an opportunity for independent verification of the estimated values by future studies.
\end{abstract}

DOI: 10.1103/PhysRevApplied.3.024003

\section{INTRODUCTION}

Semiconducting and conducting zinc oxide $(\mathrm{ZnO})$ have in the past decade been studied quite extensively due to their unique optical and electrical properties. However, the origin of the "inherent" $n$-type conductivity has been a longstanding controversy, and several potential sources of the $n$-type conductivity have been proposed. One important contributor is believed to be $\mathrm{Al}$ residing on the $\mathrm{Zn}$ site $\left(\mathrm{Al}_{\mathrm{Zn}}\right) . \mathrm{Al}$ is an abundant residual impurity in single-crystal bulk material and thin films $[1,2]$ and it is also, together with $\mathrm{Ga}$ and In, among the most commonly exploited shallow donors in $\mathrm{ZnO}$ [3-5]. In fact, one of the most successful applications of $\mathrm{ZnO}$ so far has been as a transparent conducting oxide (TCO), with typically aluminum (AZO), gallium (GZO), and to some extent indium (IZO) as dopants. $\mathrm{ZnO}$ is an environmentally friendly and abundant alternative to indium tin oxide (ITO). However, the obtained minimum resistivity of AZO is higher than that for comparable ITO films, and one of the limiting factors appears to be deactivation of the $\mathrm{Al}$ dopant by a vacancy-type defect [6]. Thus, there is a need for a deeper understanding of the general behavior and limitation of $\mathrm{Al}$ as a shallow donor in $\mathrm{ZnO}$, both from fundamental scientific and technological perspectives.
Surprisingly, fundamental studies related to configuration, solubility, and diffusivity of $\mathrm{Al}$ in $\mathrm{ZnO}$ are scarce in the literature. In an early work by Norman, the solubility and diffusivity of $\mathrm{Al}$ and $\mathrm{Ga}$ were studied by dissolving samples in a solution and analyzing the total amount of $\mathrm{Al}$ by monitoring the reduction in dichromate using photometry [7]. The diffusivity was then estimated from Fick's law of diffusion with boundary conditions applicable to unrestricted diffusion into rods. However, since only the total Al concentration was measured, this approach obviously does not reveal any details of the process of migration. Nevertheless, Norman extracted an activation energy of $2.74 \mathrm{eV}$ and a prefactor of $5.3 \times 10^{-2} \mathrm{~cm}^{2} \mathrm{~s}^{-1}$ for the diffusion constant of $\mathrm{Al}$ in $\mathrm{ZnO}$.

More recently, Lin and Bristowe [8] found that $\mathrm{Al}$ doping of $\mathrm{ZnO}$ reduces the compressive stress at interfaces with $\mathrm{Ag}$ films. Interestingly, density-functional theory (DFT) calculations also showed that both the $\mathrm{Al}$ on the substitutional $\mathrm{O}$ site $\left(\mathrm{Al}_{\mathrm{O}}\right)$ and $\mathrm{Al}$ on the interstitial site $\left(\mathrm{Al}_{i}\right)$ have substantially higher formation energies as compared to $\mathrm{Al}_{\mathrm{Zn}}$, predicting that $\mathrm{Al}_{\mathrm{Zn}}$ is the dominating configuration. This is also supported by another firstprinciple-calculations study by T-Thienprasert et al. [9], where it was further suggested, based on combined results from DFT and synchrotron x-ray absorption measurements, 
that the formation of $\mathrm{Al}_{\mathrm{Zn}} n v_{\mathrm{Zn}}(n=1,2)$ complexes is responsible for a suppressed carrier concentration in Al-doped samples. Stehr et al. [10] recently presented firm evidence, based on electron paramagnetic resonance experiments, for the existence of the $\mathrm{Al}_{\mathrm{Zn}} v_{\mathrm{Zn}}$ complex in electron irradiated samples, supporting the predictions by T-Thienprasert et al. [9].

There are several reports in the literature on diffusion of, e.g., $\mathrm{H}$ and $\mathrm{Li}$ in $\mathrm{ZnO}$. For $\mathrm{H}$, it has been shown that a trap- and solubility-limited process prevails [11]. For Li, it is found that the amphoteric properties, in which $\mathrm{Li}$ can occupy both the interstitial site $\left(\mathrm{Li}_{i}\right)$ as a donor and the substitutional site $\left(\mathrm{Li}_{\mathrm{Zn}}\right)$ as an acceptor, are important for the diffusion process. The conversion between the highly mobile $\left(\mathrm{Li}_{i}\right)$ and more stable configuration $\left(\mathrm{Li}_{\mathrm{Zn}}\right)$ results in sharp concentration gradients as a function of depth $[12,13]$. Thus, the effective diffusivity of Li depends on both the position of the Fermi level and the detailed stoichiometry, i.e., where the material is $\mathrm{O}$ or $\mathrm{Zn}$ rich. Both of these $\mathrm{H}$ and Li models yield results which deviate quite drastically from the "ordinary" infinite source model, implying that dopant or impurity diffusion in $\mathrm{ZnO}$ is generally a complex process.

Steiauf et al. [14], have recently used density-functional theory with hybrid functionals to calculate the diffusion activation energies for $\mathrm{Al}, \mathrm{Ga}$, and $\mathrm{In}$, assuming a Zn-vacancy-assisted mechanism. They predict a migration energy for $\mathrm{Al}_{\mathrm{Zn}}-v_{\mathrm{Zn}}^{-}$of $2.66 \mathrm{eV}$. This value is in line with the value obtained by Norman [7] $(2.74 \mathrm{eV})$; however, the fundamental mechanism for diffusion assumed in Refs. [7] and [14] differs and calls for further investigation.

In this paper, we study $\mathrm{Al}$ diffusion into single-crystal hydrothermally grown (HT) ZnO bulk samples, by deposition of a thin film of highly doped AZO and subsequent heat treatment. Concentration versus depth profiles, obtained by secondary-ion mass spectrometry (SIMS), are combined with hybrid DFT to unveil the diffusivity and the prevailing atomistic mechanisms of the diffusion process. Several models are evaluated with regard to the experimental data, including an alternative model based on reaction diffusion with $v_{\mathrm{Zn}}$ mediating the $\mathrm{Al}$ diffusion, emphasizing the importance of the charge state of the species involved in the migration process.

\section{METHODOLOGY}

$\mathrm{ZnO}$ films ( $\sim 0.5 \mu \mathrm{m}$ thick) doped with $\mathrm{Al}$ to a concentration of $2 \times 10^{21} \mathrm{~cm}^{-3}$ are deposited onto single-crystal hydrothermally grown $\mathrm{ZnO}$ bulk samples (Tokyo Denpa), with a residual $\mathrm{Al}$ content of about $1 \times 10^{16} \mathrm{~cm}^{-3}$. The asgrown resistivity of the bulk samples is $2 \mathrm{k} \Omega \mathrm{cm}$. Prior to deposition, the samples are cleaned in acetone, ethanol, and deionized water using an ultrasonic bath, before being loaded into a Semicore magnetron sputtering deposition chamber with a $99.99 \%$ pure $\mathrm{ZnO}$ ceramic target and a 99.999\% Al target mounted in $\mathrm{rf}$ and $\mathrm{dc}$ cathodes, respectively. The sample chamber is evacuated to a base pressure of $\sim 5 \times 10^{-5} \mathrm{~Pa}$ before an argon pressure of $2.2 \mathrm{~Pa}$ is established and deposition is undertaken at $400{ }^{\circ} \mathrm{C}$. During the $250 \mathrm{~min}$ deposition, rotation of the sample at $12 \mathrm{rpm}$ is maintained. The $\mathrm{Al}$ doping is realized via cosputtering by keeping the $\mathrm{Al}$ cathode power and the $\mathrm{ZnO}$ cathode power at a constant density of $\sim 0.18 \mathrm{~W} \mathrm{~cm}^{-2}$ and $\sim 1.1 \mathrm{~W} \mathrm{~cm}^{-2}$, respectively.

After deposition, one sample is heat treated, sequentially, for $30 \mathrm{~min}$ in the range from $800{ }^{\circ} \mathrm{C}$ up to $1300^{\circ} \mathrm{C}$ to realize diffusion of $\mathrm{Al}$ from the sputtered film into the bulk. After each heat treatment, the concentration-versus-depth profiles are acquired in a Cameca IMS7f microanalyzer with a primary sputtering beam of $10 \mathrm{keV} \mathrm{O}_{2}^{+}$ions for the detection of $\mathrm{Al}$ and Li. Crater depths are subsequently measured with a Dektak 8 stylus profilometer, and a constant erosion rate is assumed for depth calibration. The $\mathrm{Al}$ and $\mathrm{Li}$ concentration calibrations are performed using implanted reference samples, which result in an uncertainty in the concentration values of less than $10 \%$. The depth resolution is estimated to be $\sim 10 \mathrm{~nm}$. In addition to the isochronal treatment, a series of isothermal treatments is conducted at $1100^{\circ} \mathrm{C}$ for durations of $0.5,2.5,7.5$, and $17.5 \mathrm{~h}$. The concentration of residual impurities other than $\mathrm{Al}$ and $\mathrm{Li}$ in the film or in the bulk material is less than $\sim 10^{17} \mathrm{~cm}^{-3}$.

\section{A. Computational details}

First-principles calculations within the DFT formalism as implemented in the Vienna Ab Initio Simulation Package VASP $[15,16]$ are utilized to investigate the defect structure of Al-doped $\mathrm{ZnO}$. The calculations are performed with the Perdew-Burke-Ernzerhof (PBE) Heyd-Scuseria-Ernzerhof exchange-correlation functional (with a screening parameter of 0.2) [17-19], intermixing 37\% exact exchange. Furthermore, we employed the projector-augmented-wave (PAW) method [20] and a constant energy cutoff of $400 \mathrm{eV}$ for the plane waves. All ionic positions are relaxed to within residual forces of less than $0.03 \mathrm{eV} / \AA$ and with an energy convergence criterion of $10^{-6} \mathrm{eV}$, for selfconsistency. The calculations are performed using a 72atom supercell of wurtzite-structured $\mathrm{ZnO}$, and by fixing the lattice shape and volume to that of the pristine supercell.

Defect-formation energies are evaluated according to

$$
\Delta G_{\mathrm{defect}}^{f}=E_{\mathrm{defect}}^{\mathrm{tot}}-E_{\mathrm{bulk}}^{\mathrm{tot}}+\sum_{1}^{i} \Delta n_{i} \mu_{i}+q\left(\epsilon_{F}+\Delta \epsilon\right),
$$

where $E_{\text {bulk }}^{\text {tot }}$ is the electronic total energy, $\Delta n_{i}$ is the change in the number of atoms $i$ with chemical potential $\mu_{i}, q$ is the effective charge of the defect, $\epsilon_{F}$ is the Fermi-level position, and $\Delta \epsilon$ aligns the core potentials of the perfect and the defective supercells to remedy shifts in the band edges due 
to the jellium background charge. The 0-K defectformation energies presented in the following sections are only valid for O-rich conditions, where $\mu_{\mathrm{Zn}}=\mu_{\mathrm{ZnO}}^{0}-$ $\frac{1}{2} \mu_{\mathrm{O}_{2}}^{0}, \quad \mu_{\mathrm{Al}}=\frac{1}{2}\left(\mu_{\mathrm{Al}_{2} \mathrm{O}_{3}}^{0}-\frac{3}{2} \mu_{\mathrm{O}_{2}}^{0}\right), \quad \mu_{\mathrm{O}}^{0}=\frac{1}{2} \mu_{\mathrm{O}_{2}}^{0}, \quad$ and $\quad \mu_{\mathrm{H}}=$ $\frac{1}{2}\left(\mu_{\mathrm{H}_{2} \mathrm{O}}^{0}-\frac{1}{2} \mu_{\mathrm{O}_{2}}^{0}\right)$. To avoid the large uncertainty arising from overbinding of the $\mathrm{O}_{2}$ molecule in evaluation of finite temperature formation energies, we obtain $\mu_{\mathrm{O}}$ by assuming the equilibrium gas mixture $\mathrm{H}_{2} \mathrm{O}+\mathrm{H}_{2}$ in which $\mu_{\mathrm{O}}$ is given by $\mu_{\mathrm{O}}=\left(\mu_{\mathrm{H}_{2} \mathrm{O}}-2 \mu_{\mathrm{H}}\right)$.

At finite temperatures (and partial pressures), we include the temperature dependencies of $\mu_{i}$,

$$
\mu_{i}\left(T, p_{i}\right)=\mu_{i}^{0}+H_{i}(T)-T S_{i}(T)+k_{B} T \ln \left(\frac{p_{i}}{p^{0}}\right),
$$

where $\mu_{i}$ is determined by the total energy of the pure phases at $0 \mathrm{~K}$ as obtained from DFT, whereas the second and third terms are taken as tabulated values [21].

Finite temperature and partial pressure defect concentrations $c_{i}$ are obtained through

$$
\frac{c_{i}}{c_{s, i}}=N_{c, i} \exp \left(\frac{\Delta G_{i}^{f}}{k_{B} T}\right),
$$

where $c_{s, i}$ is the number of ions per unit volume (e.g., concentration of $\mathrm{Zn}$ ions) and $N_{c, i}$ is the number of configurations the defect may attain at each site. Finally, the following relation limits the defect concentrations to saturation of each regular lattice site:

$$
\sum_{1}^{N} c_{i}+c_{s, i}=c_{0, i},
$$

where $N$ is the number of distinct defects formed at each site while $c_{0, i}$ is the number of regular lattice sites per unit volume. The equilibrium Fermi-level position $\left(\epsilon_{F}\right)$ is determined by the weighted concentrations of all $M$ charged ionic defects, in addition to the electron $(n)$ and hole $(p)$ concentration,

$$
\begin{gathered}
\sum_{1}^{M} q_{j} c_{j}+p-n=0, \\
n=2\left(\frac{m_{e} k_{B} T}{2 \pi \hbar^{2}}\right)^{3 / 2} \exp \left(-\frac{E_{c}-\epsilon_{F}}{k_{B} T}\right), \\
p=2\left(\frac{m_{h} k_{B} T}{2 \pi \hbar^{2}}\right)^{3 / 2} \exp \left(\frac{E_{v}-\epsilon_{F}}{k_{B} T}\right),
\end{gathered}
$$

where $m_{e}$ and $m_{h}$ are the effective electron and electronhole masses, respectively, and put as 0.28 and 0.7 relative to the free electron mass [22]. $E_{c}$ and $E_{v}$ are the edge of the conduction and valence band, respectively. The Fermi level and the individual defect concentrations may thus be obtained by solving Eq. (5) for each ambient condition.
The FLEXPDE software is employed to numerically solve the differential equations used in the present work [23] and the input parameters are manually varied in order to minimize the difference between the calculated and experimental data.

\section{RESULTS}

Figure 1 shows the $\mathrm{Al}$ concentration as a function of depth for one sample after the isochronal heat treatments in the range of $800^{\circ} \mathrm{C}-1300^{\circ} \mathrm{C}$. The surface of the deposited film degrades after treatment at $1150^{\circ} \mathrm{C}$, and above (Fig. 1), and to facilitate a comparison between the different profiles, the interface between the deposited film and the bulk single crystal is defined as the depth where the concentration gradient of $\mathrm{Al}$ is at maximum (in absolute values). Hence, the concentration versus depth profiles obtained for temperatures $\geq 1150^{\circ} \mathrm{C}$ are adjusted accordingly. Temperatures in excess of $900^{\circ} \mathrm{C}$ are required to observe a significant migration of $\mathrm{Al}$ into the bulk, and the distributions resemble a "box profile" with increasing concentration and depth as a function of temperature. However, below $1000^{\circ} \mathrm{C}$, the profiles deviate from this general trend, possibly indicating a more complex migration process, and these profiles are disregarded in the following analysis and discussion.

The concentration of $\mathrm{Al}$ in the sputtered film is about $2 \times 10^{21} \mathrm{~cm}^{-3}$, more than 1 order of magnitude higher than the resulting concentration in the single-crystal material. The Al-doped thin film can thus be regarded as a semiinfinite source for the $\mathrm{Al}$ diffusion. Furthermore, the increasing concentration of the Al-diffusion shoulder (or plateau) as a function of temperature reflects the temperature dependence of the solubility of $\mathrm{Al}$ in singlecrystal $\mathrm{ZnO}$.

Figure 2 shows the results of a series of isothermal heat treatments carried out at $1100^{\circ} \mathrm{C}$, with an extension of $\mathrm{Al}$

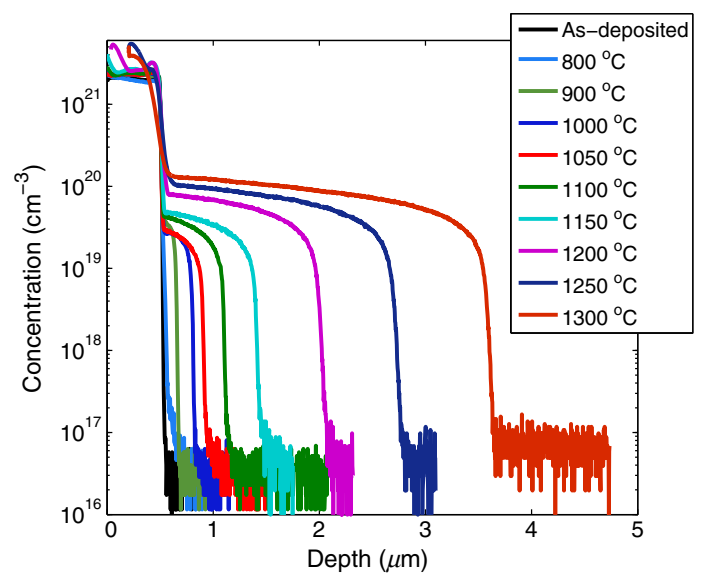

FIG. 1. Al-diffusion profiles for one sample, which has been heat treated sequentially for $30 \mathrm{~min}$ in the range of $800^{\circ} \mathrm{C}-1300^{\circ} \mathrm{C}$. 


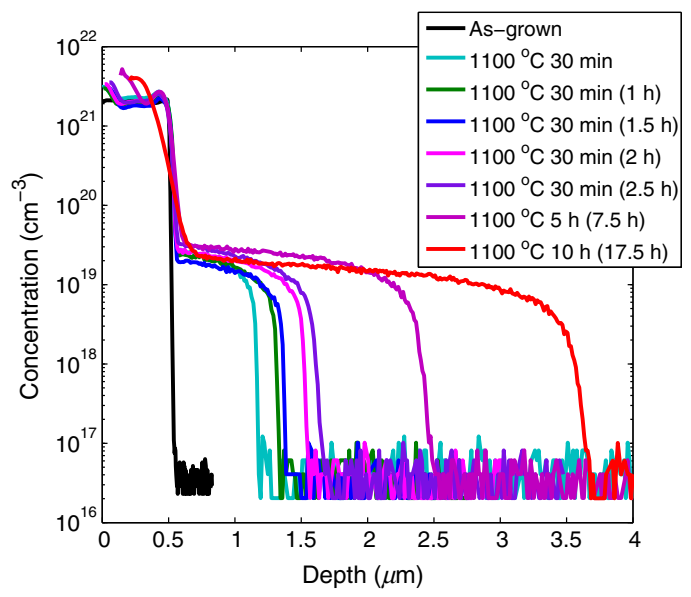

FIG. 2. The Al concentration vs depth for isothermal diffusion at $1100^{\circ} \mathrm{C}$. The duration of each stage is indicated in the label and the accumulated duration is given in parentheses.

$\sim 3.5 \mu \mathrm{m}$ into the bulk $\mathrm{ZnO}$ after a total time of $17.5 \mathrm{~h}$. Figure 3 shows the $\mathrm{Al}$ and $\mathrm{Li}$ concentration as a function of depth in the as-deposited sample and in the samples after the $1100{ }^{\circ} \mathrm{C}$ and $1200{ }^{\circ} \mathrm{C}$ heat treatments $(30 \mathrm{~min})$. First of all, these results unveil that the $\mathrm{Li}$ concentration in the sputtered film is minute $\left(\leq 1 \times 10^{15} \mathrm{~cm}^{-3}\right)$ in the asdeposited state, while the as-grown single crystal contains $2 \times 10^{17} \mathrm{~cm}^{-3}$. After heat treatment, Li migrates to, and accumulates in, the deposited film, reaching a concentration of approximately $3 \times 10^{18} \mathrm{~cm}^{-3}$. Interestingly, $\mathrm{Li}$ also accumulates in the Al-doped region of the high-quality single-crystal material; e.g., after $1200{ }^{\circ} \mathrm{C}$, the concentration reaches about $4 \times 10^{18} \mathrm{~cm}^{-3}$. In addition, in a region deeper than the Al-doped layer, an increased concentration of $\mathrm{Li}$ is observed, reaching a concentration of about $5 \times 10^{17} \mathrm{~cm}^{-3}$. This latter effect is also clearly pronounced after $1100^{\circ} \mathrm{C}$, where two distinct steps in the Li profile are

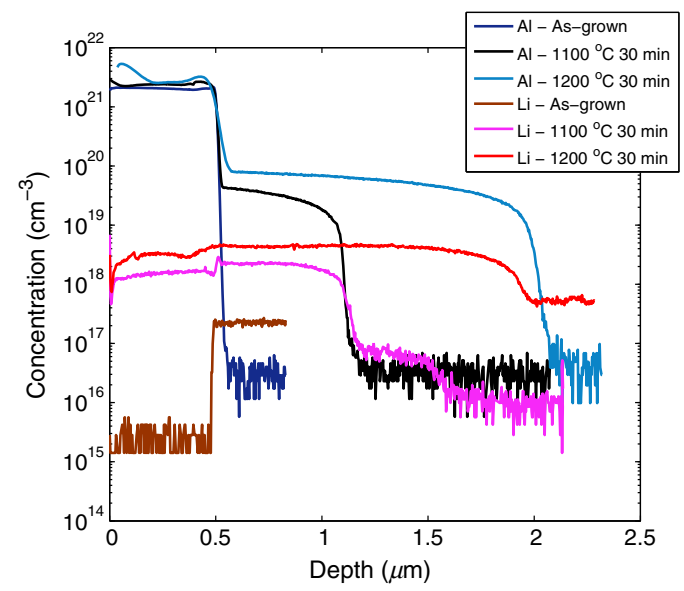

FIG. 3. The $\mathrm{Al}$ and $\mathrm{Li}$ concentration vs depth profiles for the as-deposited sample and after the $1100^{\circ} \mathrm{C}$ and $1200^{\circ} \mathrm{C}$ diffusion steps. visible. The first step at about $1 \times 10^{18} \mathrm{~cm}^{-3}$ corresponds closely with the Al-doped region $(0.5-1.2 \mu \mathrm{m})$, while the second at $6 \times 10^{16} \mathrm{~cm}^{-3}$, occurs in a region deeper than the Al-doped layer (about 1.2-1.5 $\mu \mathrm{m}$ ). Beyond the second step, the Li concentration is only about $1 \times 10^{16} \mathrm{~cm}^{-3}$, which is more than 1 order of magnitude lower than in the as-grown single-crystal bulk material $\left(2 \times 10^{17} \mathrm{~cm}^{-3}\right)$. In general, the amount of $\mathrm{Li}$ accumulation, both in the film and in the Al-doped regions of the bulk material, varies with the heat-treatment temperature.

\section{DISCUSSION}

\section{A. Al-Li interaction}

It has recently been found that $\mathrm{Li}$ can be used as a probe for monitoring the defect dynamics in $\mathrm{ZnO}[24,25]$ and a combined SIMS and positron annihilation spectroscopy (PAS) study of HT samples showed that Li predominately resides on the $\mathrm{Zn}$ site in the as-grown sample state [26,27]. Furthermore, in air, ambient temperatures of $1200{ }^{\circ} \mathrm{C}-1500^{\circ} \mathrm{C}$ are required in order to out-diffuse $\mathrm{Li}$ from highly resistive HT-grown samples [28], reflecting the high thermal stability of $\mathrm{Li}_{\mathrm{Zn}}$. A similar conclusion was also drawn in a dedicated study of in-diffusion of $\mathrm{Li}$ under oxygen rich conditions [13]. In contrast, under $\mathrm{Zn}$-rich conditions, $\mathrm{Zn}_{i}$ will kick out $\mathrm{Li}_{\mathrm{Zn}}$ to $\mathrm{Li}_{i}$, which is highly mobile $[12,13]$.

The observed accumulation of $\mathrm{Li}$ in the Al-doped region can then be attributed to an increase in the Fermi-level position relative to the valence-band edge caused by the shallow $\mathrm{Al}_{\mathrm{Zn}}^{+}$donor. This will, in turn, lower the formation energy of $\mathrm{Li}_{\mathrm{Zn}}^{-}$leading to a higher concentration, which also has the effect of compensating the $\mathrm{Al}_{\mathrm{Zn}}^{+}$donor. In other words, $\mathrm{Li}_{i}$ interacts with $v_{\mathrm{Zn}}$ by forming $\mathrm{Li}_{\mathrm{Zn}}$. Hence, the observed increase in $\mathrm{Li}$ concentration implies a local increase of the $v_{\mathrm{Zn}}$ concentration in the Al-doped region and a depletion of Li deep into the bulk of the material after treatment at temperatures $\geq 1200^{\circ} \mathrm{C}$.

The accumulation of $\mathrm{Li}$ in the second plateau (deeper than the $\mathrm{Al}$ profile), as shown in Fig. 3, is rather weak and may possibly be due to the Debye tail caused by diffusion of conduction band electrons out of the Al-doped region. The increase of the Fermi-level position in this region relative to the bulk will lead to an increase in the equilibrium $\mathrm{Li}_{\mathrm{Zn}}$ concentration, in the same manner as described above for the Al-rich layer. Further studies will be pursued to confirm (or rule out) this interpretation.

\section{B. Diffusion models}

In this section, we will discuss the validity of various models to describe the observed diffusion behavior of $\mathrm{Al}$, aiming to gain a physical understanding of the ongoing atomistic processes. Several models have been proposed in the literature to predict the diffusion of different impurities in $\mathrm{ZnO}$, specifically, and for semiconductors in general. 


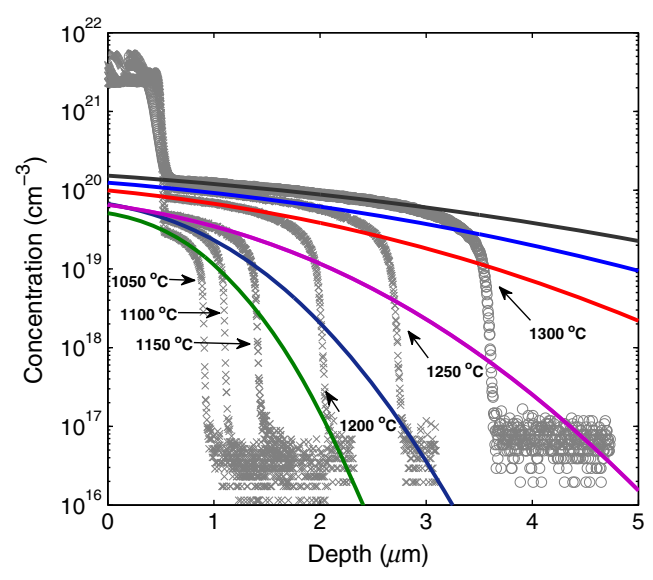

FIG. 4. Experimental Al-diffusion profiles fitted with the analytical solution of the semi-infinite source model.

The most common approach, which was also utilized by Norman for $\mathrm{Al}$ in $\mathrm{ZnO}$ [7], is the semi-infinite source model.

\section{Semi-infinite source model}

As shown in Figs. 1 and 2, the $\mathrm{Al}$ concentration in the sputtered film is more than 1 order of magnitude higher than the apparent solubility limit of $\mathrm{Al}$ in the single-crystal bulk sample for the studied temperature range. Therefore, as a first approximation, one may assume that the $\mathrm{Al}$ profiles will be described by the semi-infinite source model with the analytical solution,

$$
C(x)=\mathcal{S}_{\mathrm{Al}} \operatorname{erfc}\left(\frac{x}{\sqrt{2 D_{\mathrm{Al}} t}}\right),
$$

where $\mathcal{S}_{\mathrm{Al}}$ is the solubility of $\mathrm{Al}$ in $\mathrm{ZnO}, x$ is the depth, $D_{\mathrm{Al}}$ is the aluminum diffusivity, and $t$ is the diffusion time. However, profiles can only be fitted up to a certain depth, e.g., $\sim 1.5 \mu \mathrm{m}$ for $1150^{\circ} \mathrm{C}$; see Fig. 4 . At this depth, there is a sharp decrease in the $\mathrm{Al}$ concentration, where the calculated profiles deviate strongly from the experimental ones. The semi-infinite source model follows directly from Fick's law of diffusion and represents what one can refer to as free or unrestricted diffusion. One way to view the comparison in Fig. 4 is that the model describes the measured profiles correctly where the diffusion is unrestricted, until they fall below a threshold. The threshold increases with temperature and may be attributed to a rise in the Fermi-level position due to in-diffusion of $\mathrm{Al}$ donors, resembling the situation for Li diffusion [13].

Values extracted for the diffusion and solid solubility using the semi-infinite source model (above the threshold) are shown in Figs. 5 and 6. Data from Norman are also included for comparison [7]. It should be noted that Norman [7] measured the total concentration of in-diffused $\mathrm{Al}$ (without any information about the depth distribution) and used a different set of boundary conditions due to different sample geometry compared to our study.

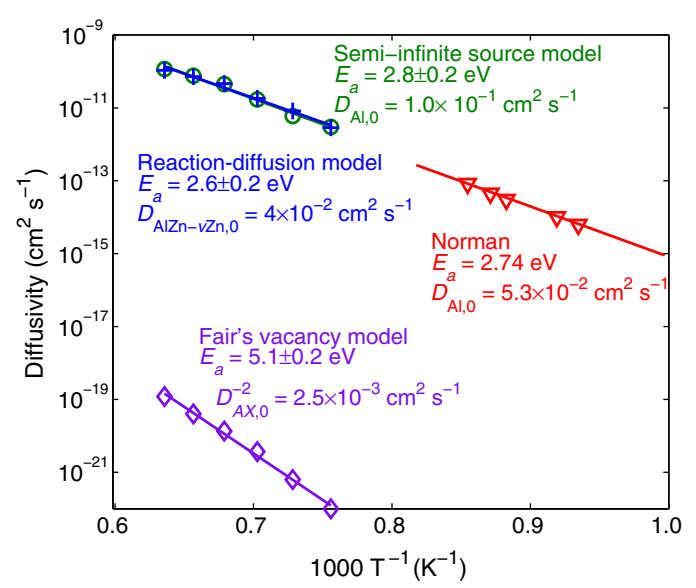

FIG. 5. Diffusivity of $\mathrm{Al}$ in $\mathrm{ZnO}$ as extracted from the semi-infinite source model, Fair's vacancy model, the reactiondiffusion model, and the study by Norman [7]. Activation energies are estimated for the separate data sets. There is a very close overlap between the data from the semi-infinite source model and the reaction-diffusion model. These two models are also in line with the values estimated by Norman. However, values obtained using Fair's vacancy model deviate strongly. This deviation arises from the physical difference in the definition of $D$ in Fair's vacancy model as compared to the other models. In principle, the models cannot be compared, and they are only depicted together here to emphasize the vast difference between them. The given uncertainties reflect the quality of the data fitting.

\section{Trap-limited diffusion}

Trap-limited diffusion (TLD) is a process which can lead to high gradients in the profiles of in-diffused species. It has previously been found that $\mathrm{H}$ diffusion in $\mathrm{ZnO}$ can be

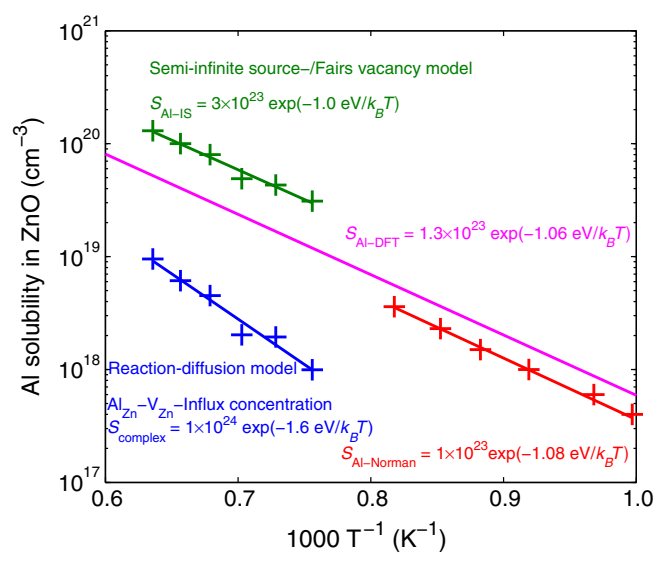

FIG. 6. Solubility values of $\mathrm{Al}$ in $\mathrm{ZnO}$ as estimated from the semi-infinite source model, Fair's vacancy model, and the reactiondiffusion model. The values from the semi-infinite source model and Fair's vacancy model overlap closely and cannot be distinguished from each other. The values extracted from the reactiondiffusion model reflect the influx concentration of the $\left(\mathrm{Al}_{\mathrm{Zn}} v_{\mathrm{Zn}}\right)^{-1}$ complex. Results from the study by Norman [7] are included for comparison. The purple line shows the total Al concentration, obtained by DFT and thermodynamical equilibrium calculations. 


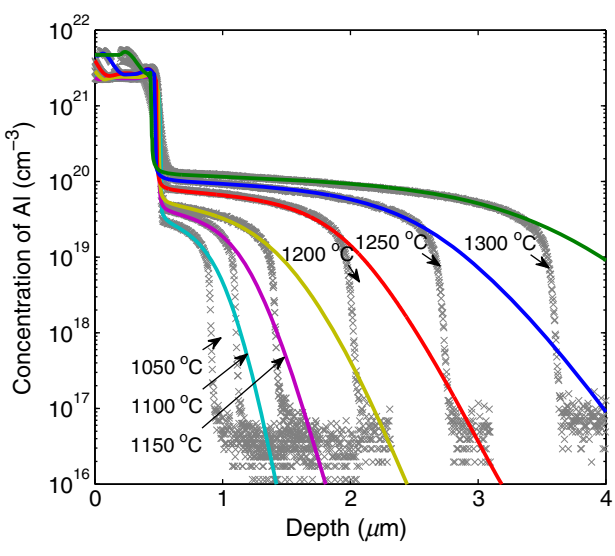

FIG. 7. Results from the trap-limited diffusion model, used in an attempted fit to the experimental data in the range of $1000^{\circ} \mathrm{C}-1300^{\circ} \mathrm{C}$. The deviation between the model and experimental data is clearly increasing as a function of the diffusion temperature and the model is ruled out.

explained through a solubility- and trap-limited process [11]. However, it is not possible to properly describe the experimental Al data with a similar TLD model; see Fig. 7. The model assumes an initial background of traps with constant concentration. However, in the given example, the trap concentration varies as a function of temperature from about $3 \times 10^{19} \mathrm{~cm}^{-3}$ to $1 \times 10^{20} \mathrm{~cm}^{-3}$, while the residual concentration of impurities measured in these samples is $\leq 1 \times 10^{17} \mathrm{~cm}^{-3}$. Moreover, the TLD model predicts that the gradient of the diffusion front should decrease as a function of time (and temperature). Such a change in the gradient is not observed during the isothermal treatment (Fig. 2), excluding also intrinsic defects as traps. Hence, the TLD model is, therefore, disregarded as the correct one for diffusion of $\mathrm{Al}$ in $\mathrm{ZnO}$.

\section{Fair's vacancy model}

Studies of phosphorus (P) diffusion in silicon ( $\mathrm{Si}$ ) led to the development of what is known as Fair's vacancy model [29]. At the atomistic level, the process can be described in three steps: (i) substitutional phosphorus $\left(\mathrm{P}_{\mathrm{Si}}\right)$ attracts and forms a complex with a vacancy $\left(v_{\mathrm{Si}}\right)$, (ii) $\mathrm{P}_{\mathrm{Si}}$ moves from its original site to the vacant site, before (iii) the complex dissociates and the vacancy continues to diffuse and drive the $\mathrm{P}$ migration. In general, the process is limited either by the diffusivity of the (charged) vacancy or the dissociation of the complex. In this phenomenological model, the diffusivity depends on the charge state of the vacancy and the effective diffusivity is given as the sum over the different charge states. For the case of a positively charged donor (like $\mathrm{Al}_{\mathrm{Zn}}$ ) and negatively charged vacancies (like $v_{\mathrm{Zn}}$ ) one obtains

$$
D_{A}^{\mathrm{eff}}=h \sum_{q} D_{A^{+} X^{-q}}^{q}\left(\frac{n}{n_{i}+N_{\mathrm{eff}}}\right)^{-q}
$$

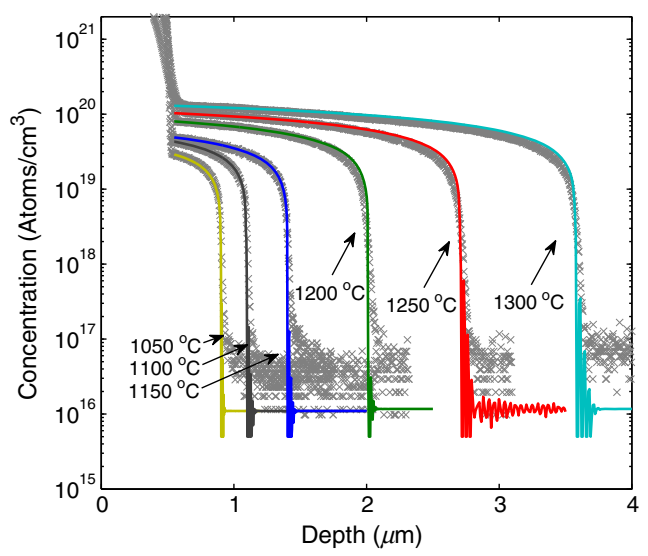

FIG. 8. Comparison between Fair's vacancy model and the experimental data in the temperature range of $1050{ }^{\circ} \mathrm{C}-1300{ }^{\circ} \mathrm{C}$. The model has been restricted to only the -2 charge state of the $v_{\mathrm{Zn}}$. A good agreement is obtained over the whole diffusion profiles at all of the different temperatures.

where $h$ is known as the electric-field enhancement factor, $q$ is the charge state of the diffusing vacancy $(q= \pm 1,2,3, \ldots), n_{i}$ is the intrinsic carrier concentration, $n$ is the free carrier concentration provided by the dopants and $N_{\text {eff }}$ is the effective residual donor and/or acceptor concentration (excluding $n$ ). Furthermore, assuming complete ionization and activation with no compensation, $n$ equals the dopant concentration. As will be shown in the next section, it is sufficient to consider only the -2 charge state of $v_{\mathrm{Zn}}$ for the given experimental conditions, and in Fig. 8 the measured diffusion profiles between $1050{ }^{\circ} \mathrm{C}$ and $1300^{\circ} \mathrm{C}$ are compared with the simulated ones using only the -2 charge state of $v_{\mathrm{Zn}}$. Furthermore, $n_{i}$ can be calculated from the relation $n_{i}=\sqrt{N_{C} N_{V}} \exp \left(-\frac{E_{\mathrm{g}}}{2 k_{B} T}\right)$, where $N_{C}$ and $N_{V}$ are the effective density of states in the conduction and valence-band edge, respectively. $E_{g}$ is the band gap and $T$ the temperature in kelvin. It is not trivial to estimate the band-gap-narrowing effect for $\mathrm{ZnO}$ in the temperature range $1100^{\circ} \mathrm{C}-1300^{\circ} \mathrm{C}$; data in Ref. [30] for the optical band gap extend up to $500^{\circ} \mathrm{C}$, and for $\sim 100^{\circ} \mathrm{C}$ and higher, the data can be described by

$$
\Delta E_{g}(T)=183.33-\frac{2}{3} \mathrm{~T}(\mathrm{meV})
$$

As a first approximation, $E_{g}$ values of $2.57-2.43 \mathrm{eV}$ are obtained in the temperature interval of $1100^{\circ} \mathrm{C}-1300^{\circ} \mathrm{C}$ by extrapolation of Eq. (10). Including this approximation of the band-gap-narrowing effect, the intrinsic carriers amount to about $10^{15}-10^{16} \mathrm{~cm}^{-3}$ at $1100^{\circ} \mathrm{C}-1300^{\circ} \mathrm{C}$. Assuming an electron mobility of $100 \mathrm{~cm}^{2} / \mathrm{V}$ s it can be estimated from the as-grown resistivity $(\sim 2 \mathrm{k} \Omega \mathrm{cm})$ that the effective residual concentration of donors in the as-grown material amounts to about $3 \times 10^{13} \mathrm{~cm}^{-3}$ at room temperature and, if the majority of compensating acceptors (like $\mathrm{Li}_{\mathrm{Zn}}$ ) have 
energy levels in the lower part of $E_{g}$, the effective-donorbackground concentration is substantially lower than $n_{i}$ at elevated temperatures and its contribution can be disregarded.

The modeling and experimental results in Fig. 8 are in good agreement. In Fig. 5, the extracted diffusivities are plotted as a function of inverse temperature, from which an activation energy of $5.1 \mathrm{eV}$ with a preexponential factor of $2.5 \times 10^{-3} \mathrm{~cm}^{2} \mathrm{~s}^{-1}$ is deduced. The extracted activation energy is high and interpreted as a sum of energies for several mechanisms involved in the diffusion, as will be further discussed in Sec. IV D. The solubility values extracted from Fair-Tsai model overlap closely with those from the semi-infinite source model, as shown in Fig. 6, and are also in reasonable agreement with those reported by Norman [7]. Fair's vacancy model describes the overall diffusion of $\mathrm{Al}$ in a proper manner, however, its phenomenological nature does not reveal the details of the governing processes.

\section{Defect structures from DFT in Al-rich $\mathrm{ZnO}$}

Hybrid DFT calculations are employed to investigate possible defect structures in Al-rich ZnO. Figure 9 shows defect formation energies evaluated at $0 \mathrm{~K}$ under O-rich conditions. The formation energy of $\mathrm{Al}_{\mathrm{Zn}}$ is found to be considerably lower than those of $\mathrm{Al}_{\mathrm{O}}$ and $\mathrm{Al}_{i}$. The

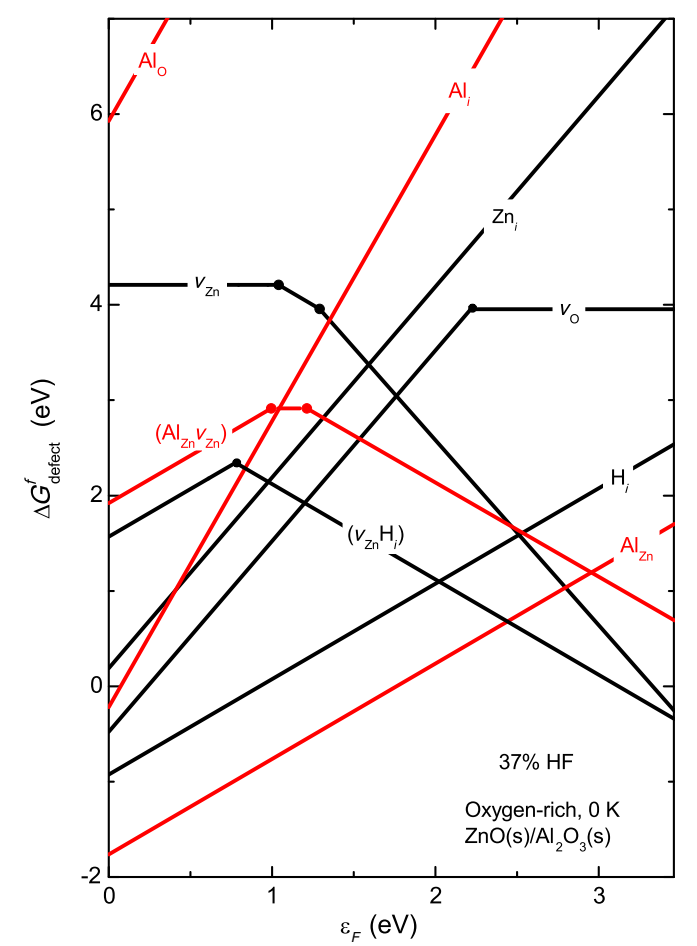

FIG. 9. Formation energies of various intrinsic, Al-related defects and complexes in $\mathrm{ZnO}$ evaluated at $0 \mathrm{~K}$ in the oxygenrich limit $\left(\mathrm{H}_{2} \mathrm{O}+\mathrm{O}_{2}\right)$. The formation energy is shown for the 0 , -1 , and -2 charge states of $v_{\mathrm{Zn}}$, and the $+2,+1,0$, and -1 states for the other defects (when applicable). high value for $\mathrm{Al}_{\mathrm{O}}$, even at low Fermi-level positions, indicates that the concentration of $\mathrm{Al}_{\mathrm{O}}$ is insignificant. Although the formation energy of $\mathrm{Al}_{i}$ is low at $\epsilon_{F}$ close to the valence-band edge, it surpasses $4 \mathrm{eV}$ in $n$-type material such that $\mathrm{Al}_{i}$ also can be disregarded under O-rich conditions.

The $\mathrm{Al}_{\mathrm{Zn}} v_{\mathrm{Zn}}$ complex displays deep transition levels close to those of $v_{\mathrm{Zn}}$. However, in $n$-type material, the $\left(\mathrm{Al}_{\mathrm{Zn}} v_{\mathrm{Zn}}\right)^{-1}$ is the preferred species, and its formation energy decreases with increasing $\epsilon_{F}$. The dissociation energy of the $\left(\mathrm{Al}_{\mathrm{Zn}} v_{\mathrm{Zn}}\right)^{-1}$ complex according to

$$
\left(\mathrm{Al}_{\mathrm{Zn}} v_{\mathrm{Zn}}\right)^{-1} \Rightarrow \mathrm{Al}_{\mathrm{Zn}}^{+1}+v_{\mathrm{Zn}}^{-2}
$$

is found to be $0.75 \mathrm{eV}$, slightly higher than the value of $0.56 \mathrm{eV}$ reported by T-Thienprasert et al. using a generalized gradient approximation (GGA) PBE functional [9]. It should also be noted that, for low Fermi-level positions, $\mathrm{Al}_{\mathrm{Zn}} v_{\mathrm{Zn}}$ becomes positively charged, as also found for the complex between one interstitial $\mathrm{H}$ donor $\left(\mathrm{H}_{i}\right)$ and $v_{\mathrm{Zn}}$, denoted as $v_{\mathrm{Zn}}-\mathrm{H}_{i}$. This charge state can be viewed as a neutral $v_{\mathrm{Zn}}$, together with the positively charged $\mathrm{Al}_{\mathrm{Zn}}$ or $\mathrm{H}_{i}$.

Figure 10 shows the thermal-equilibrium concentration of the most relevant defects in $\mathrm{Al}$-rich $\mathrm{ZnO}$ as a function of inverse temperature, assuming equilibrium with $\mathrm{Al}_{2} \mathrm{O}_{3}(\mathrm{~s})$, in an ambient with $p_{\mathrm{O}_{2}}=1 \mathrm{~atm}$ and $p_{\mathrm{H}_{2} \mathrm{O}}=0.01 \mathrm{~atm}$ (and no frozen-in defects). Throughout major parts of the temperature interval, the $\mathrm{Al}_{\mathrm{Zn}}$ donor is predicted to be partially compensated by $v_{\mathrm{Zn}}$ and $v_{\mathrm{Zn}}-\mathrm{H}_{i}$, as minority defects. By neglecting phonon contribution in the calculations, the concentrations of all defects, and particularly $v_{\mathrm{Zn}}$, are somewhat underestimated. Hence, partial compensation of $\mathrm{Al}_{\mathrm{Zn}}$ by $v_{\mathrm{Zn}}$ is expected, such that a complete $1: 1$

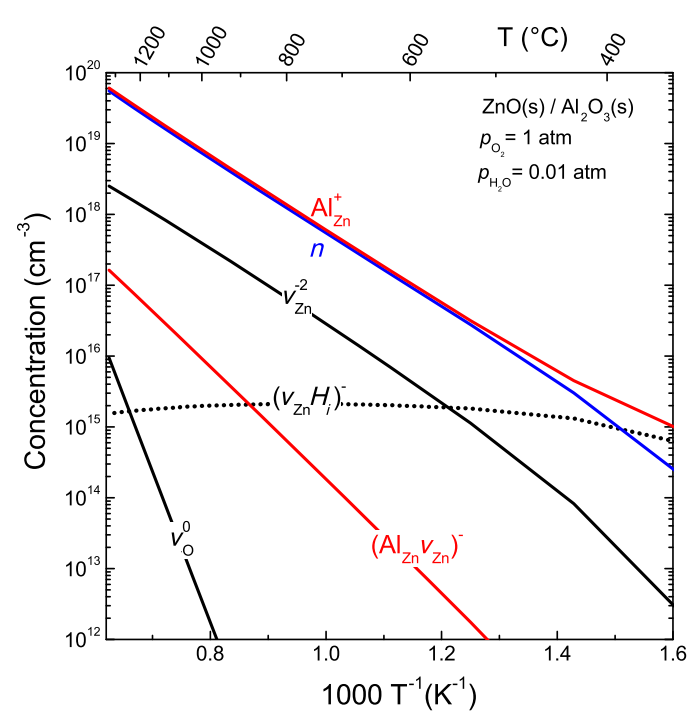

FIG. 10. Thermal-equilibrium defect and free electron concentration in $\mathrm{ZnO}$ as a function of inverse absolute temperature. Equilibrium is assumed with $\mathrm{Al}_{2} \mathrm{O}_{3}$ in 1 atm $\mathrm{O}_{2}$ and 0.01 atm $\mathrm{H}_{2} \mathrm{O}$. 
charge-carrier-to-dopant ratio upon $\mathrm{Al}$ doping of $\mathrm{ZnO}$ will not occur, as discussed in detail in the next section. The $\left(\mathrm{Al}_{\mathrm{Zn}} v_{\mathrm{Zn}}\right)^{-1}$ complex exists as a minority defect upon dissolution of $\mathrm{Al}$ from $\mathrm{Al}_{2} \mathrm{O}_{3}$. In a frozen-in situation with no $\mathrm{Al}$ source, however, $v_{\mathrm{Zn}}$ and $\mathrm{Al}_{\mathrm{Zn}}$ would associate and $\left(\mathrm{Al}_{\mathrm{Zn}} v_{\mathrm{Zn}}\right)^{-1}$ becomes the dominating $\mathrm{Al}$ center at low temperatures (cf. also Fig. 9 with $\epsilon_{F}$ close to $\mathrm{E}_{c}$ ). Furthermore, these results show that the concentrations of $\mathrm{Al}_{i}$ and $\mathrm{Al}_{\mathrm{O}}$ are minute (outside the range of Fig. 10) under oxidizing conditions, and they are therefore of no importance for $\mathrm{Al}$ dissolution in $\mathrm{ZnO}$.

As illustrated in Fig. 6, there is a reasonably close correlation between the DFT and the measured values for the solid solubility of $\mathrm{Al}$, where the latter values are represented by those extracted from the semi-infinite source model. The agreement holds for both the prefactor and the activation energy with values of $\sim 10^{23} \mathrm{~cm}^{-3}$ and $\sim 1 \mathrm{eV}$, respectively.

\section{D. $\mathrm{Al}_{\mathrm{Zn}} v_{\mathrm{Zn}}$ reaction-diffusion model}

In the following, the aim is to describe the experimental results by a physical model based on reaction diffusion and the actual concentration of the involved species. In analogy with Fair's model, a vacancy-mediated process is assumed, spurred by the redistribution of $\mathrm{Li}$ into the $\mathrm{Al}$-doped region (Fig. 3) and the predictions of our DFT calculations. Furthermore, we invoke only the strongly prevailing double negative $v_{\mathrm{Zn}}$.

The Fermi-level position is governed by the charge neutrality, and for the studied system, it can be written as

$$
n=\left[\mathrm{Al}_{\mathrm{Zn}}^{+1}\right]-2\left[v_{\mathrm{Zn}}^{-2}\right]-\left[\left(\mathrm{Al}_{\mathrm{Zn}} v_{\mathrm{Zn}}\right)^{-1}\right]+N_{d}^{+1},
$$

where $\left[\mathrm{Al}_{\mathrm{Zn}}\right],\left[v_{\mathrm{Zn}}^{-2}\right],\left[\mathrm{Al}_{\mathrm{Zn}} v_{\mathrm{Zn}}^{-1}\right]$, and $\mathrm{N}_{d}^{+1}$ are the concentration of the substitutional $\mathrm{Al}$ donor, the $\mathrm{Zn}$ vacancy, $\mathrm{Al}_{\mathrm{Zn}}-v_{\mathrm{Zn}}$, and the effective background-donor concentration (excluding the contribution from $\mathrm{Al}_{\mathrm{Zn}}$ ), respectively. Under the current conditions, we can neglect the contribution of holes $(p)$. As discussed previously, $\mathrm{N}_{d}^{+1}$ is in the $10^{13}-10^{14} \mathrm{~cm}^{-3}$ range, and furthermore, no Fermi-level pinning is assumed. Two diffusing species are accounted for: $v_{\mathrm{Zn}}^{-2}$ and $\left(\mathrm{Al}_{\mathrm{Zn}} v_{\mathrm{Zn}}\right)^{-1}$. First, the time evolution of the $\mathrm{Al}_{\mathrm{Zn}} v_{\mathrm{Zn}}$ concentration can be described by the reactiondiffusion equation,

$$
\frac{\partial\left[\mathrm{Al}_{\mathrm{Zn} v_{\mathrm{Zn}}}\right]}{\partial t}=D_{\mathrm{Al}_{\mathrm{Zn} v_{\mathrm{Zn}}}} \frac{\partial^{2}\left[\mathrm{Al}_{\mathrm{Zn} v_{\mathrm{Zn}}}\right]}{\partial x^{2}}-R\left(\left[\mathrm{Al}_{\mathrm{Zn}} v_{\mathrm{Zn}}\right]\right),
$$

where $D_{\mathrm{Al}_{Z n v_{Z n}}}$ is the diffusivity of the $\mathrm{Al}_{\mathrm{Zn}} v_{\mathrm{Zn}}$ complex and the term $R\left(\left[\mathrm{Al}_{\mathrm{Zn}} v_{\mathrm{Zn}}\right]\right)$ can be expressed as

$R\left(\left[\mathrm{Al}_{\mathrm{Zn}} v_{\mathrm{Zn}}\right]\right)=\frac{\partial\left[\mathrm{A}_{\mathrm{Zn}}\right]}{\partial t}=\nu\left[\mathrm{Al}_{\mathrm{Zn} v_{\mathrm{Zn}}}\right]-K\left[\mathrm{Al}_{\mathrm{Zn}}\right]\left[v_{\mathrm{Zn}}\right]$,

where $\nu$ is the dissociation rate and $K$ is given by

$$
K=4 \pi r D_{v_{\mathrm{Zn}}},
$$

where $r$ is the capture radius in the trapping process and $D_{v_{\mathrm{Zn}}}$ is the diffusivity of $v_{\mathrm{Zn}}$.

Second, the $\left[v_{\mathrm{Zn}}\right]$ is assumed to be controlled by the local Fermi-level position, i.e., the net electron concentration as given by Eq. (12), as a function of depth. Thus, $\left[v_{\mathrm{Zn}}^{q}\right]$ for different charge states $q$ will be governed by their formation enthalpies $\left[E_{\text {formation }}\left(q, \epsilon_{F}\right)\right]$, which strongly depend on $\epsilon_{F}$ (except for $v_{\mathrm{Zn}}^{0}$ ). This implies instantaneous establishment of a $v_{Z n}$ equilibrium concentration dictated by the local Fermi-level position in the following manner:

$$
\begin{aligned}
{\left[v_{\mathrm{Zn}}^{q}\right] } & =N_{\text {sites }} e^{-\frac{E_{\text {formation }}\left(q, \epsilon_{F}\right)}{k_{B} T}}, \\
E_{\text {formation }}\left(q, \epsilon_{F}\right) & =E_{\text {formation }, 0}^{q}+q \epsilon_{F}, \\
\epsilon_{F} & =E_{c}+k_{B} T \times \ln \frac{n}{2\left(\frac{m_{e} k_{B} T}{2 \pi \hbar^{2}}\right)^{3 / 2},} \\
{\left[v_{\mathrm{Zn}}^{q}\right] } & =N_{\text {sites }} e^{-\frac{E_{\text {formation. } 0}^{q}+q E_{\mathrm{c}}}{k_{B} T}} e^{-q \times \ln \left(\frac{n^{n}}{\left.2 \frac{m_{e} B_{B} T}{2 \pi \hbar^{2}}\right)^{3 / 2}}\right)}, \\
A & =N_{\text {sites }}\left[2\left(\frac{m_{e} k_{B} T}{2 \pi \hbar^{2}}\right)^{3 / 2}\right]^{q} e^{-\frac{E_{\text {formation }, 0}^{q}+q E_{\mathrm{c}}}{k_{B} T}}, \\
{\left[v_{\mathrm{Zn}}^{q}\right] } & =A n^{-q},
\end{aligned}
$$

where $N_{\text {sites }}$ is the total number of $\mathrm{Zn}$ sites per unit volume in the material, $m_{e}$ is the effective electron mass in the conduction band, and $E_{c}$ is the position of the conduction band edge at the temperature of diffusion. $E_{\text {formation, } 0}$ is the formation energy of $v_{\mathrm{Zn}}$ when $\epsilon_{F}=0$, i.e., at the valenceband edge. The total-vacancy concentration is then in principle given as a sum over all the relevant charge states, but Fig. 9 reveals that $v_{\mathrm{Zn}}^{-2}$ is strongly prevailing in $n$-type material, and the other charge states will be omitted in the following.

The model leaves us with the following fitting parameters: $D_{\mathrm{Al}_{\mathrm{Zn}} v_{\mathrm{Zn}}}, \nu, D_{v_{\mathrm{Zn}}}, r$, and $A$ [i.e., $\left(E_{\text {formation }}^{-2}-2 E_{c}\right)$, in practice]. In addition, the influx of $\mathrm{Al}_{\mathrm{Zn}} v_{\mathrm{Zn}}$ from the deposited Al-doped film is treated as a boundary condition. There is a strong coupling between the different parameters and several sets of values are found to give the same quality of solutions or fit of the experimental data. Hence, a unique solution does not exist, but several of the exponential prefactors of the processes involved, e.g., those of $D_{v_{\mathrm{Zn}}}$, $D_{\mathrm{Al}_{\mathrm{Zn} \mathrm{z}_{\mathrm{Zn}}}}$, and $\nu$, are found to play a decisive role. Using the constraint that the prefactors should adapt physically viable values, many of the solutions can be disregarded. Furthermore, values of reasonable confidence can be deduced for the activation energies of $D_{v_{\mathrm{Zn}}}, D_{\mathrm{Al}_{\mathrm{Zn}} v_{\mathrm{Zn}}}$, and $\nu$, supporting the validity of the model.

The parameter $A$ is based on the relative electron mass $\left(m_{e}=0.28\right.$ from Ref. [22]), $E_{\text {formation }, 0}$, and $E_{C}(T)$. The latter is deduced from Eq. (10), assuming a band gap at $R T$ of $3.3 \mathrm{eV}$ and a fixed valence-band maximum. $E_{\text {formation, } 0}$ 
TABLE I. Parameters used to fit the experimental data with the reaction-diffusion model.

$$
\begin{gathered}
r=1 \mathrm{~nm} \\
\nu=10^{13} e^{-\left[0.75(\mathrm{eV}) / k_{B} T\right]} \mathrm{s}^{-1} \\
E_{\text {formation, } 0}=6.44 \mathrm{eV} / 6.20 \mathrm{eV} \\
N_{d}^{+}=3 \times 10^{13} \mathrm{~cm}^{-3}
\end{gathered}
$$

is merely treated as a fitting parameter, but guided by values obtained from our hybrid DFT calculations. Finally, the trapping radius $r$ is typically found to be in the range of 1-2 nm between charged defects [31] at elevated temperatures and in the following $r$ is put to $1 \mathrm{~nm}$. A background effective-donor concentration of $N_{d}^{+}=3 \times 10^{13} \mathrm{~cm}^{-3}$ is assumed for all the simulations and an overview of the input parameter values is given in Table I. However, it should also be mentioned that $N_{d}^{+}$must be higher than $\sim 1 \times 10^{17} \mathrm{~cm}^{-3}$ to have any visible effect on the result of the simulations. Since the isochronal heat treatments are carried out sequentially at increasing temperature for the same sample, the simulations are performed accordingly, where the result from one temperature step is taken as input for the subsequent one. As input for the initial $1050^{\circ} \mathrm{C}$ step, the result of a $1000{ }^{\circ} \mathrm{C}$ simulation is used, where the starting values of $\left[\mathrm{Al}_{\mathrm{Zn}}\right],\left[\mathrm{Al}_{\mathrm{Zn}} v_{\mathrm{Zn}}\right]$, and $\left[v_{\mathrm{Zn}}\right]$ are given by a Gaussian function centered at the thin-film-bulk interface with a width of $10 \mathrm{~nm}$ and peak concentrations of $2 \times 10^{19} \mathrm{~cm}^{-3}, 1 \times 10^{18} \mathrm{~cm}^{-3}$, and $1 \times 10^{17} \mathrm{~cm}^{-3}$, respectively. All the simulations assume the interface $(x=0.5 \mu \mathrm{m})$ as the starting position.

In principle, also $D_{v_{\mathrm{Zn}}}$ could have been treated as an input parameter (and not a fitting one), but literature data scatter over a quite wide range. Activation-energy values have been reported from $1.9 \mathrm{eV}$ to $3.3 \mathrm{eV}$, where the migration barrier, as estimated by first-principles calculations, is expected to account for about $1 \mathrm{eV}$; see, e.g., Refs. [32] and [33].

Furthermore, the sputter-deposited Al-doped $\mathrm{ZnO}$ films used are considered as an infinite source of $\mathrm{Al}$, providing mobile $\mathrm{Al}_{\mathrm{Zn}} v_{\mathrm{Zn}}$ complexes. The in-flux of $\left[\mathrm{Al}_{\mathrm{Zn}} v_{\mathrm{Zn}}\right]$ at the interface $(x=0.5 \mu \mathrm{m})$ is treated as a fitting parameter for each temperature and the obtained values are recognized as an apparent solubility of the $\mathrm{Al}_{\mathrm{Zn}} v_{\mathrm{Zn}}$ complex, depicted in Fig. 6. These values should not be confused with those obtained by Norman [7], and also the ones estimated by us using the infinite source model, which refer to the total concentration of Al. However, a comparison between $\left[\mathrm{Al}_{\mathrm{Zn}} v_{\mathrm{Zn}}\right]$ and the total $\mathrm{Al}$ concentration is considered to be relevant since an intimate relationship between the two is anticipated.

Figure 11 shows results of the simulations after diffusion at $1200{ }^{\circ} \mathrm{C}(30 \mathrm{~min})$ for the total [Al], [ $\left.v_{\mathrm{Zn}}\right]$, $\left[\mathrm{Al}_{\mathrm{Zn}} v_{\mathrm{Zn}}\right]$, and $\left[\mathrm{Al}_{\mathrm{Zn}}\right]$ as a function of depth, together with the predicted electron concentration $n$, and the

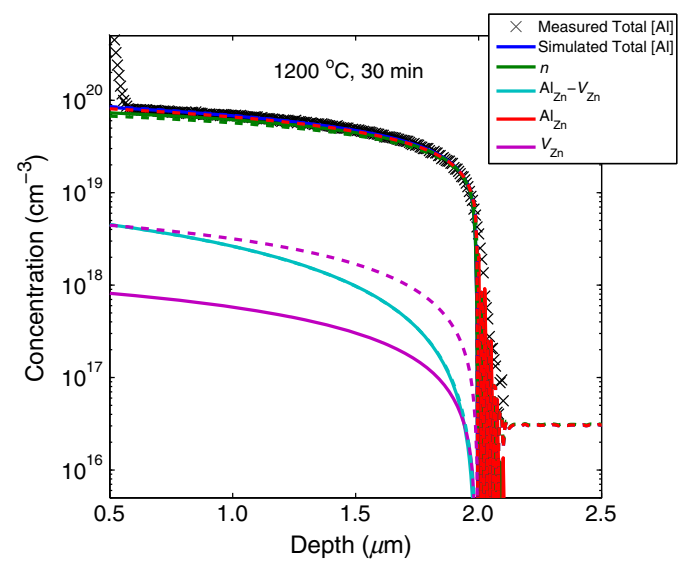

FIG. 11. Results for the reaction-diffusion model, which show the depth distribution of the electron concentration and that of each of the involved defects after diffusion at $1200^{\circ} \mathrm{C}(30 \mathrm{~min})$. The solid lines represent solutions with $E_{\text {formation, } 0}=6.44 \mathrm{eV}$, while the dotted lines represent $E_{\text {formation, } 0}=6.20 \mathrm{eV}$. The total $\mathrm{Al}$ concentration and the measured $\mathrm{Al}$ concentration overlap closely in both cases.

experimental values of [Al]. The mobile species are the $\mathrm{Al}_{\mathrm{Zn}} v_{\mathrm{Zn}}$ complex and $v_{\mathrm{Zn}}$, while the $\mathrm{Al}_{\mathrm{Zn}}$ donor is practically immobile, even at these relatively high temperatures. Two different simulations are undertaken assuming values for $E_{\text {formation, } 0}=6.2$ or $E_{\text {formation, } 0}=6.44 \mathrm{eV}$, dotted and solid lines, respectively, where the latter value is predicted by the DFT calculations (Fig. 9). A close agreement holds between the total measured [Al] and the total simulated [Al] for both values of $E_{\text {formation, } 0}$. In fact, the only major difference between the two simulations is $\left[v_{\mathrm{Zn}}\right]$, which is increased by about half an order of magnitude when decreasing the value from $6.44 \mathrm{eV}$ to $6.2 \mathrm{eV}$. Figure 12 shows the extracted values for $D_{v_{\mathrm{Zn}}}$ from the two simulations, where only $D_{v_{\mathrm{Zn}}}$ has

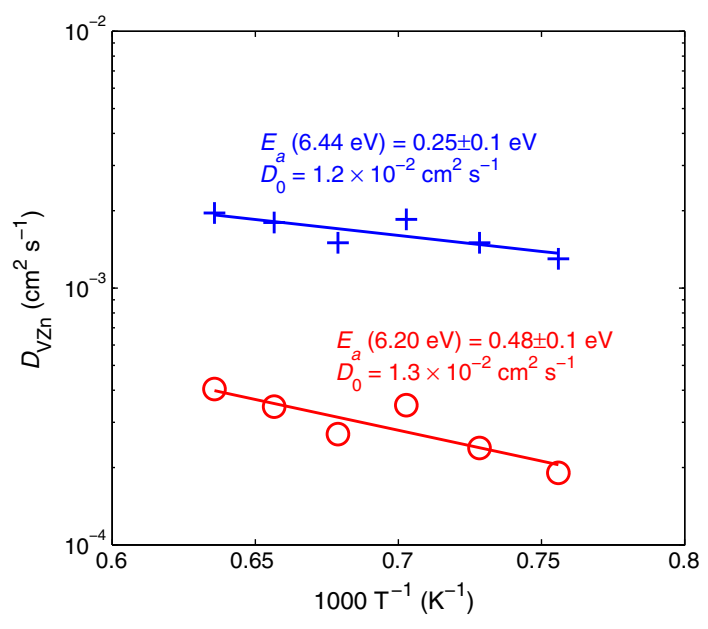

FIG. 12. Extracted values for the $v_{\mathrm{Zn}}$ diffusion (migration) under the assumption of $E_{\text {formation, } 0}=6.44 \mathrm{eV}$ (blue crosses) and $E_{\text {formation, } 0}=6.2 \mathrm{eV}$ (red circles). 


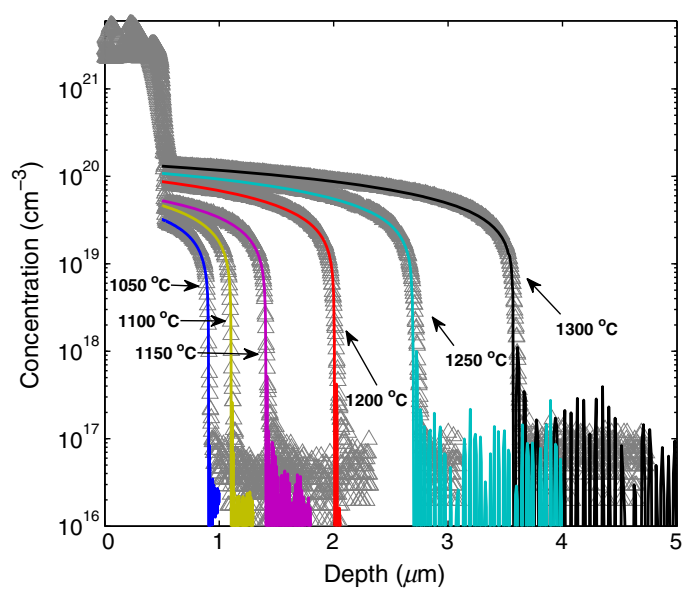

FIG. 13. The total Al-concentration profiles from the reactiondiffusion model fitted to the experimental data in the studied temperature range $\left(1000{ }^{\circ} \mathrm{C}-1300^{\circ} \mathrm{C}\right)$. Each step is sequentially simulated for a diffusion time of $30 \mathrm{~min}$ to comply with the experimental conditions. The parameter values used in the simulation are given in Table I. The profiles for $E_{\text {formation }, 0}=$ $6.44 \mathrm{eV}$ and $E_{\text {formation }, 0}=6.2 \mathrm{eV}$ are indistinguishable.

been varied to account for the difference in $E_{\text {formation, } 0}$. A lower formation energy (higher $\left[v_{\mathrm{Zn}}\right]$ ) yields a lower $D_{\mathrm{Zn}}$ and, for both combinations of parameters, fits of [Al] of similar quality are obtained; see Figs. 12 and 13. Within the accuracy of the comparison, there is a minor or no change in the prefactor of $D_{v_{\mathrm{Zn}}}$, while the activation energy increases from $0.25 \mathrm{eV}$ to $0.48 \mathrm{eV}$, corresponding directly to the change from $6.44 \mathrm{eV}$ to $6.20 \mathrm{eV}$. This exemplifies that a change in the vacancyformation energy causes an opposite change in the activation energy for the vacancy migration and their sum remains constant. This can also be related directly from Eq. (14), where the reaction term $R$ can remain unchanged by compensating an increase in $\left[v_{\mathrm{Zn}}\right]$ by a decrease in $D_{v_{\mathrm{Zn}}}$. Similarly, since there is a direct coupling between the dissociation rate $\nu$ and $D_{v_{\mathrm{Zn}}}$ (through the term $R\left(\left[\mathrm{Al}_{\mathrm{Zn}} v_{\mathrm{Zn}}\right]\right.$ in Eq. (13)) an increase (decrease) in the activation energy for $D_{v_{\mathrm{Zn}}}$ could also be reflected by a corresponding increase (decrease) in the dissociation energy for $\mathrm{Al}_{\mathrm{Zn}} v_{\mathrm{Zn}}$, which has been fixed at $0.75 \mathrm{eV}$, as predicted by the DFT calculations.

Using $E_{\text {formation, } 0}=6.44 \mathrm{eV}$, the average concentration of $v_{\mathrm{Zn}}\left(\sim\left[8 \times 10^{17} \mathrm{~cm}^{-3}\right]\right)$ and $\mathrm{Al}_{\mathrm{Zn}} v_{\mathrm{Zn}}\left(\sim\left[3 \times 10^{18} \mathrm{~cm}^{-3}\right]\right)$ is more than 1 order of magnitude below that of $\mathrm{Al}_{\mathrm{Zn}}$. The two deep acceptor defects partly compensate the shallow $\mathrm{Al}_{\mathrm{Zn}}$ donor and thus reduce the free electron concentration, although the compensation ratio is low relative to that experimentally observed for highly Ga-doped $\mathrm{ZnO}$ films [6]. The compensation by $v_{\mathrm{Zn}}$ increases, however, when decreasing $E_{\text {formation, } 0}$ to $6.2 \mathrm{eV}$, indicating that the formation energy obtained from the DFT calculations is slightly overestimated. Here, it should be kept in mind that the calculations assume $0 \mathrm{~K}$ crystal temperature. The same conclusion may also be drawn from the estimate of the activation energy for $v_{\mathrm{Zn}}$ diffusion, where $E_{\text {formation, } 0}=$ $6.44 \mathrm{eV}$ results in a migration barrier of only $0.25 \mathrm{eV}$. Alternatively, as discussed, this barrier could also be increased by increasing the dissociation energy of $\mathrm{Al}_{\mathrm{Zn}} v_{\mathrm{Zn}}(0.75 \mathrm{eV})$.

In Fig. 13, all the simulated profiles of [Al] using the reaction-diffusion model with the parameter values given in Table I are compared to measurements in the whole range of studied temperatures, $1050{ }^{\circ} \mathrm{C}$ to $1300^{\circ} \mathrm{C}$, and a close agreement is demonstrated. In Fig. 5, the extracted values for the $\mathrm{Al}_{\mathrm{Zn}} v_{\mathrm{Zn}}$ diffusivities are depicted, together with the diffusivities obtained from the previously discussed models and an activation energy of $2.6 \mathrm{eV}$ with a prefactor of $4 \times 10^{-2} \mathrm{~cm}^{2} \mathrm{~s}^{-1}$ is obtained. These values are close to those from the semi-infinite source model $(2.8 \mathrm{eV}$ and $\left.1 \times 10^{-1} \mathrm{~cm}^{2} \mathrm{~s}^{-1}\right)$ as well as from Norman [7] (2.74 eV and $5 \times 10^{-2} \mathrm{~cm}^{2} \mathrm{~s}^{-1}$ ), and further supported by the recent calculations preformed by Steiauf et al. [14]. As mentioned, the activation energy extracted from Fair's vacancy model, on the other hand, deviates drastically from the other models, and the $D$ values are about 8 orders of magnitude lower than those of the other models; see Fig. 5. However, a direct comparison of the $D$ values in Fig. 5 is not valid; for the reaction-diffusion model and the semi-infinite source model they represent the migration for the diffusing $\mathrm{Al}_{\mathrm{Zn}} v_{\mathrm{Zn}}$ species while, for Fair's model, all thermally activated processes (like $v_{\mathrm{Zn}}$ formation and migration, $\mathrm{Al}_{\mathrm{Zn}} v_{\mathrm{Zn}}$ formation, migration, and dissociation) are included in the $D$ parameter. Accordingly, Fair's model is beneficial from a technological perspective, requiring only one fitting parameter, but it provides limited insight into the physical process governing the diffusivity, in direct contrast to that of the reaction-diffusion model. For instance, the reaction diffusion hinges strongly on defect concentrations, like $\left[v_{\mathrm{Zn}}\right]$, which can be measured and confirmed by other experimental techniques like PAS. Thus, both the intrinsic properties of the materials system studied and the model itself can be corroborated by independent studies using other experimental and theoretical techniques, than employed in this study. This model is obviously not applicable to $\mathrm{ZnO}$ only, but to a large range of materials systems, where vacancy-assisted diffusion prevails.

\section{CONCLUSION}

$\mathrm{Li}$ is exploited as a marker for studying the interaction between $\mathrm{Al}$ and intrinsic defects in $\mathrm{ZnO}$, and the results have stimulated the development of an alternative model for diffusion of Al. The model is based on reaction diffusion and it unveils the atomistic mechanisms involved in the diffusion process. A vacancy-mediated process is found to prevail and the evolution of species like $\mathrm{Al}_{\mathrm{Zn}}, v_{\mathrm{Zn}}$, and $\mathrm{Al}_{\mathrm{Zn}} v_{\mathrm{Zn}}$ can be followed as a function of temperature, 
time, and depth, in contrast to more phenomenological approaches like Fair's vacancy model. The migration of $\mathrm{Al}$ occurs via the $\mathrm{Al}_{\mathrm{Zn}} v_{\mathrm{Zn}}$ complex while $\mathrm{Al}_{\mathrm{Zn}}$ is practically immobile, and $\mathrm{Al}_{i}$ and $\mathrm{Al}_{\mathrm{O}}$ exhibit negligible concentrations with formation energies in excess of $8 \mathrm{eV}$ in the studied samples. The formation of $\mathrm{Al}_{\mathrm{Zn}} v_{\mathrm{Zn}}$ is promoted by high Fermi-level positions, giving rise to abrupt changes in the $\mathrm{Al}$ concentration profile in transition regions between highly and lightly $n$-doped layers. The model gives support to the early study by Norman [7] in estimating the activation energy for migration of $\mathrm{Al}$ to approximately $2.6 \mathrm{eV}$ with a preexponentional factor of $4 \times 10^{-2} \mathrm{~cm}^{2} \mathrm{~s}^{-1}$. These values can now be attributed to the migration of negatively charged $\mathrm{Al}_{\mathrm{Zn}} v_{\mathrm{Zn}}$ complexes, and the strong presence of these complexes in $n$-type layers is corroborated by results from DFT calculations of defect formation energies. The model developed for $\mathrm{Al}$ diffusion in $\mathrm{ZnO}$ can be generalized to all materials systems where vacancymediated impurity diffusion prevails, enabling deep insight into both the intrinsic properties of the studied materials system and the diffusion properties of the impurity in question.

\section{ACKNOWLEDGMENTS}

Financial support is acknowledged from the FRINATEK program in the Research Council of Norway through the DYNAZOx (Project No. 221992) and the HydraThermPro (Project No. 214252) projects. Both the Norwegian Metacenter for Computational Science (for providing computational resources and excellent support under the Project No. NN4604k) and the Research Council of Norway (for the support to the Norwegian Micro- and Nano-Fabrication Facility, NorFab, 197411/V30) are gratefully acknowledged for providing essential infrastructure access.

[1] L. Vines, E. V. Monakhov, R. Schifano, W. Mtangi, F. D. Auret, and B. G. Svensson, Lithium and electrical properties of ZnO, J. Appl. Phys. 107, 103707 (2010).

[2] M. McCluskey and S. Jokela, Sources of $n$-type conductivity in $\mathrm{ZnO}$, Physica (Amsterdam) 401B-402B, 355 (2007).

[3] R. Schifano, M. Schofield, L. Vines, S. Diplas, E. V. Monakhov, and B. G. Svensson, $\mathrm{Al}$ and $\mathrm{Si}$ doping of sputtered $\mathrm{ZnO}$ thin films, IOP Conf. Ser. 34, 012007 (2012).

[4] B. Claflin and D. C. Look, in Zinc Oxide Materials for Electronic and Optoelectronic Device Applications, edited by C. W. Litton, D. C. Reynolds, and T. C. Collins (John Wiley \& Sons, New York, 2011), p. 6186.

[5] L. Vines and A. Y. Kuznetsov, Bulk Growth and Impurities in Oxide Semiconductors, Vol. 88 (Academic Press, New York, 2013).
[6] D. C. Look, K. D. Leedy, L. Vines, B. G. Svensson, A. Zubiaga, F. Tuomisto, D. R. Doutt, and L. J. Brillson, Self-compensation in semiconductors: The $\mathrm{Zn}$ vacancy in Ga-doped ZnO, Phys. Rev. B 84, 115202 (2011).

[7] V. Norman, The diffusion of aluminium and gallium in zinc oxide, Aust. J. Chem. 22, 325 (1969).

[8] Z. Lin and P. D. Bristowe, A first principles study of the properties of $\mathrm{Al}: \mathrm{ZnO}$ and its adhesion to $\mathrm{Ag}$ in an optical coating, J. Appl. Phys. 106, 013520 (2009).

[9] J. T-Thienprasert, S. Rujirawat, W. Klysubun, J. N. Duenow, T. J. Coutts, S. B. Zhang, D. C. Look, and S. Limpijumnong, Compensation in Al-Doped $\mathrm{ZnO}$ by Al-Related Acceptor Complexes: Synchrotron X-Ray Absorption Spectroscopy and Theory, Phys. Rev. Lett. 110, 055502 (2013).

[10] J. E. Stehr, K. M. Johansen, T. S. Bjørheim, L. Vines, B. G. Svensson, W. M. Chen, and I. A. Buyanova, Zinc-VacancyDonor Complex: A Crucial Compensating Acceptor in ZnO, Phys. Rev. Applied 2, 021001 (2014).

[11] K. M. Johansen, J. S. Christensen, E. V. Monakhov, A. Y. Kuznetsov, and B. G. Svensson, Deuterium diffusion and trapping in hydrothermally grown single crystalline $\mathrm{ZnO}$, Appl. Phys. Lett. 93, 152109 (2008).

[12] J. J. Lander, Reactions of lithium as a donor and an acceptor in ZnO, J. Phys. Chem. Solids 15, 324 (1960).

[13] K. E. Knutsen, K. M. Johansen, P. T. Neuvonen, B. G. Svensson, and A. Y. Kuznetsov, Diffusion and configuration of Li in ZnO, J. Appl. Phys. 113, 023702 (2013).

[14] D. Steiauf, J. L. Lyons, A. Janotti, and C. G. V. d. Walle, First-principles study of vacancy-assisted impurity diffusion in $\mathrm{ZnO}$, APL Mater. 2, 096101 (2014).

[15] G. Kresse and J. Furthmüller, Efficient iterative schemes for $a b$ initio total-energy calculations using a plane-wave basis set, Phys. Rev. B 54, 11169 (1996).

[16] G. Kresse and D. Joubert, From ultrasoft pseudopotentials to the projector augmented-wave method, Phys. Rev. B 59, 1758 (1999).

[17] J. P. Perdew, K. Burke, and M. Ernzerhof, Generalized Gradient Approximation Made Simple, Phys. Rev. Lett. 77, 3865 (1996).

[18] J. Heyd, G. E. Scuseria, and M. Ernzerhof, Erratum: Hybrid functionals based on a screened Coulomb potential, J. Chem. Phys. 124, 219906(E) (2006).

[19] J. Heyd, G. E. Scuseria, and M. Ernzerhof, Hybrid functionals based on a screened Coulomb potential, J. Chem. Phys. 118, 8207 (2003).

[20] P. E. Blöchl, Projector augmented-wave method, Phys. Rev. B 50, 17953 (1994).

[21] M. W. Chase, Jr., NIST-JANAF Thermochemical Tables (AIP, New York, 1998).

[22] G. Beni and T. M. Rice, Theory of electron-hole liquid in semiconductors, Phys. Rev. B 18, 768 (1978).

[23] FLEXPDE, http://www.pdesolutions.com.

[24] A. Y. Azarov, K. E. Knutsen, P. T. Neuvonen, L. Vines, B. G. Svensson, and A. Y. Kuznetsov, Impurity Sublattice Localization in $\mathrm{ZnO}$ Revealed by Li Marker Diffusion, Phys. Rev. Lett. 110, 175503 (2013).

[25] P. T. Neuvonen, L. Vines, B. G. Svensson, and A. Y. Kuznetsov, Intrinsic Point-Defect Balance in SelfIon-Implanted ZnO, Phys. Rev. Lett. 110, 015501 (2013). 
[26] K. M. Johansen, A. Zubiaga, I. Makkonen, F. Tuomisto, P. T. Neuvonen, K. E. Knutsen, E. V. Monakhov, A. Y. Kuznetsov, and B. G. Svensson, Identification of substitutional $\mathrm{Li}$ in $n$-type $\mathrm{ZnO}$ and its role as an acceptor, Phys. Rev. B 83, 245208 (2011).

[27] T. S. Bjørheim, S. Erdal, K. M. Johansen, K. E. Knutsen, and T. Norby, $\mathrm{H}$ and Li related defects in $\mathrm{ZnO}$ and their effect on electrical properties, J. Phys. Chem. C 116, 23764 (2012).

[28] B. G. Svensson et al., Hydrothermally grown singlecrystalline zinc oxide: Characterization and modification, MRS Online Proc. Libr. 1035, 1035-L04-01 (2007).

[29] R. B. Fair and J. C. C. Tsai, A quantitative model for the diffusion of phosphorus in silicon and the emitter dip effect, J. Electrochem. Soc. 124, 1107 (1977).
[30] R. Hauschild, H. Priller, M. Decker, J. Brückner, H. Kalt, and C. Klingshirn, Temperature dependent band gap and homogeneous line broadening of the exciton emission in ZnO, Phys. Status Solidi C 3, 976 (2006).

[31] M. S. Janson, A. Hallén, M. K. Linnarsson, and B. G. Svensson, Hydrogen diffusion, complex formation, and dissociation in acceptor-doped silicon carbide, Phys. Rev. B 64, 195202 (2001).

[32] G.-Y. Huang, C.-Y. Wang, and J.-T. Wang, First-principles study of diffusion of zinc vacancies and interstitials in $\mathrm{ZnO}$, Solid State Commun. 149, 199 (2009).

[33] B. Puchala and D. Morgan, Atomistic modeling of as diffusion in ZnO, Phys. Rev. B 85, 064106 (2012). 